\title{
Population aging in local areas and subjective well-being of older adults: Findings from two studies in Japan
}

\author{
Tami Saito ${ }^{1, *}$, Hidehiro Sugisawa ${ }^{2}$, Ken Harada ${ }^{3}$, Ichiro Kai ${ }^{4}$ \\ ${ }^{1}$ Department of Social Science, National Center for Geriatrics and Gerontology, Aichi, Japan; \\ ${ }^{2}$ Gerontology Program, J. F. Oberlin University, Tokyo, Japan; \\ ${ }^{3}$ Faculty of Humanities and Social Sciences, Jissen Women's University, Tokyo, Japan; \\ ${ }^{4}$ The University of Tokyo, Tokyo, Japan.
}

\begin{abstract}
Summary Subjective well-being (SWB) of older adults could be affected by both individual and community characteristics. However, the effect of community characteristics, such as population aging in local areas, remains unclear. This study examined the cross-sectional and longitudinal associations between the area-level population aging and SWB of older individuals from two distinct surveys. Those analyzed were 572 respondents aged 75 years and older for a cross-sectional survey in a metropolitan area in Tokyo, Japan (Study 1) and 1,257 and 859 respondents for a cross-sectional and longitudinal analysis, respectively, for a 2-year longitudinal survey project in urban and rural areas of Fukui Prefecture (Study 2). Area-level population aging was assessed by the number of people aged 65 years or older per 100 residents. SWB was assessed with the Life Satisfaction Index-A (LSIA). Multilevel analysis was performed to examine unconditional and conditional associations between the area-level number of older adults per 100 residents and the individual-level LSIA scores. The area-level number of older adults per 100 residents was significantly and positively associated with the LSIA scores in Study $1(p=0.042)$, even after controlling for the area- and individual-level covariates. In Study 2 , we also found a significant effect of the area-level number of older adults per 100 residents on LSIA scores in the longitudinal multivariate analysis $(p=0.049)$. Findings from two survey projects suggested cross-validity in the positive effect of area-level population aging on older adults' SWB. Policymakers should consider older citizens' SWB in the recent urban-to-rural migration governmental policy as well as in urban renovation planning.
\end{abstract}

Keywords: Area-level characteristics, multilevel analysis, old-old

\section{Introduction}

Subjective well-being (SWB) is a subjective view of evaluating one's life that includes emotional responses, domain satisfaction, and global judgments of life satisfaction. It is an essential component of quality of life in people (1). Particularly in gerontology, SWB has

Released online in J-STAGE as advance publication March $15,2016$.

*Address correspondence to:

Dr. Tami Saito, Department of Social Science, National Center for Geriatrics and Gerontology,

7-430 Morioka-cho, Obu, Aichi 474-8511, Japan.

E-mail: t-saito@ncgg.go.jp been regarded as an important concept (2-4). George (2) suggested that SWB should be considered as a dimension of successful aging because a large number of older adults showed high levels of subjective well-being despite physical, cognitive, and/or social deficits. This implies that SWB is a related but distinct concept of objective health indicators. Therefore, in aging societies, improvement in older adults' SWB is important.

Studies on SWB in gerontology have clarified a variety of factors for more than half a century. In 1978, Larson (4) reviewed studies on correlates of SWB and suggested that economic conditions, health or physical disability, marital status, social activities and interactions, and environmental factors such as availability of transportation or housing quality as factors affecting SWB. Brown (5) also showed in her review 
that neighborhood poverty and elderly concentration could affect the SWB of older adults. Older adults may be more susceptible to their imminent environment than younger people because many older adults are retired and spend most of their time within their community, and their reduced physical and cognitive abilities may make it difficult to handle environmental demands (6). Therefore, consideration of the relevant community environment for senior residents could be a promising strategy for improving their SWB.

However, the relationship between area-level characteristics, such as local area population aging, and the SWB of elderly residents remains unclear. Most studies conducted prior to the 1990s assessed neighborhood characteristics by examining individual perceptions, such as community satisfaction $(7,8)$ or fear of crime (9); such indicators are affected not only by neighborhood characteristics, but also by individual characteristics such as sex (9). In addition, most studies on elderly concentration and SWB have been focused on senior housing or retirement communities that are designed to meet the needs of elderly people who preferred to live there. Studies carried out by Lawton and colleagues (9-11) showed that, in neighborhoods with a higher elderly concentration, older residents tended to have greater activity participation $(9,10)$, interactions with friends (11), and subjective well-being $(9,10)$. These areas may have extensive elderly services (12), offer broader social interaction with peers who share their values and experiences (13), and ensure less discrimination against the elderly (14). However, these could be different in general communities. Lastly, most of these findings were obtained from Western countries; there have been comparatively few studies conducted in Asian countries such as Japan, where cultures and norms are different from Western countries.

In Japan, over a quarter of the population is aged 65 years and older (15). Local-area population aging in Japan has generally progressed by a combination of a decrease in fertility rate and prolonged life expectancy with enduring rural-to-urban outflow by younger generations to the present. Thus, until recently, the majority of communities with progressed population aging in Japan were located in rural areas. However, population aging has also become an urban phenomenon, where the majority of older adults live $(15,16)$. Therefore, in Japan, it is important to examine the effect of localarea population aging in both urban and rural areas.

However, unfortunately, the effect of area-level population aging in Japan remains unclear since few studies have examined the effect of area-level characteristics on individuals' health (17), except for studies on social capital $(18,19)$ or neighborhood socioeconomic deprivations (20). Moreover, the majority of these studies used a cross-sectional design. The strength of using a longitudinal design is to examine causal inference because it partially controls for the effect of unmeasured confounding variables by including the baseline outcome score in the analytical model, which enhances internal validity $(21,22)$.

In this study, our first objective was to examine the cross-validity of the associations between local-area population aging and the SWB of senior residents living in general communities in Japan. The second objective was to examine those associations using a longitudinal study design. For those examined objectives, we used data from two distinct survey projects with almost identical outcome and explanatory variables. The first dataset was obtained from a local metropolitan municipal unit, and we examined the association between small-area population aging and SWB (Study 1). The strength of using this dataset was that we could examine the association under no variations in health and welfare policy by local governments or geographic conditions, which may have confounded the findings. On the other hand, using data from a metropolitan municipal unit may limit the generalizability of the findings. Therefore, we examined the reproducibility of the findings obtained in the first study by using a second dataset that examined urban-to-rural diverse areas and the effect of area-level population aging from a longitudinal perspective (Study 2).

\section{Methods}

\subsection{Participants}

\subsubsection{Study 1}

Sumida Ward is located in downtown Tokyo, the capital of Japan, and possesses the characteristics of an inner city, including high proportions of blue-collar workers, unemployed individuals, welfare recipients, and lowquality housing; however, social disorganization (i.e., crime) in Sumida Ward is less common than it is in the equivalent large inner cities of London, New York, etc. (23). Sumida Ward consists of 26 small districts corresponding to the administrative units where civic organizations are established and local events are organized. These units are similar to the area levels where the majority of older adults spend their daily lives (24).

We selected 1,000 non-institutionalized people aged 75 years and older using a stratified random sampling method from the Resident Basic Book of Sumida Ward under the ward's permission. We conducted a faceto-face structured interview survey in July 2001, and obtained 618 responses from targeted older adults (response rate, 61.8\%), 156 proximal responses from their family members or caregivers, and 226 nonresponses. During the interview process, we excluded people who could not respond to the interview because of moderate to severe cognitive or physical impairment. The major reasons for the proximal responses were 
that the targeted older adult had a disease $(n=36)$, a functional impairment $(n=32)$, or was institutionalized $(n=30)$. The major reasons for non-response were refusal $(n=110)$, inability to make contact $(n=37)$, and death during the sample selection or survey period $(n=23)$. In this survey, we only used responses from the targeted older adults. Among the respondents, 12 individuals living in one district were excluded because neighborhood census data were unavailable. In addition, 33 respondents who were homebound because of poor physical functioning and/or who had lived at their present address for less than 3 years at the time of the study were excluded because care utilization or a relocation effect could confound the findings. One respondent who did not respond to the outcome variable was also excluded. Following these exclusions, data from 572 respondents living in 25 districts were analyzed.

\subsubsection{Study 2}

Fukui Prefecture is located in Northern Central Japan. Taxable income per taxpayer in Fukui is higher than the national average (25), which implies that people in Fukui are relatively affluent, and the majority of older adults live with their children or other relatives. Fukui is the $27^{\text {th }}$ highest in population per $1 \mathrm{~km}^{2}$ of inhabitable land area among the 47 prefectures in Japan (25), meaning that Fukui is characterized as having average to rural characteristics among prefectures. Fukui had 35 municipal units for more than 30 years until 2004 and has since merged into 17 municipalities. The municipal government is the smallest unit of policymaking in Japan. Most current municipalities contain multiple former municipal units where distinct health policies, welfare policies, and cultural events have been conducted for over 30 years. Therefore, we regarded each of the 35 former municipal units as a unit of area-level. Owing to the limited number of analyzed respondents in this study and unavailability for the appropriate area-level data, we did not examine smaller units of area such as districts or neighborhoods.

In the original survey, non-institutionalized adults aged 65 years and older $(n=5,682)$ were randomly selected from the 17 local municipalities in Fukui Prefecture based on each municipality's Resident Basic Book. The baseline survey (T1) was conducted by mailing potential participants a self-administered questionnaire during May and June 2010. We obtained 3,534 responses (response rate, 62.2\%). The reasons for non-response were unspecified, as the individuals simply did not mail back the survey. The follow-up survey (T2) was conducted between February and March 2012, with a sample of 3,387 respondents from T1, excluding those who died, were institutionalized, or withdrew from the study during the follow-up period $(n=147)$ (response rate, $75.9 \%$ ); therefore, 2,571 adults responded to both surveys. Details of the survey are shown elsewhere (26). Among the respondents in the cross-sectional study, we only included respondents who were aged 75 years or older $(n=1,729)$. Among them, we excluded those who were homebound, lived at their present address for less than three years, or did not provide sufficient information about these variables $(n=303)$. In addition, we excluded those who provided no information about the former municipal unit where they had lived or did not provide information relating to the outcome variable $(n=169)$. For the longitudinal study, we excluded 1,712 respondents for the same reasons. These inclusion and exclusion criteria were the same as used in Study 1. This resulted in 1,257 cases for cross-sectional analysis, and 859 cases for longitudinal analysis.

\subsection{Measurement}

\subsubsection{Measurement of area-level variables}

Based on previous studies $(17,22)$, area-level population aging was assessed according to the number of people aged 65 years or older per 100 residents, although the respondents in this study were aged 75 years old or older. We obtained data from the 2000 and 2010 population censuses for Studies 1 and 2, respectively, in accordance with the survey period $(25,27)$. We also assessed socioeconomic (SES) conditions and population density as confounding factors to the area-level number of people aged 65 years or older per 100 residents. Arealevel SES conditions were assessed because of its relationship with both psychological health (28) and number of older adults per 100 residents (25). In this study, the following SES variables were assessed: average household income, which was obtained from a representative resident survey conducted in 2002 in Sumida Ward (29) (Study 1) or taxable income per taxpayer in 1998 (25) as a proxy for the average household income owing to the unavailability of more immediate data (Study 2); the proportion of people with educational degrees beyond high school (27); and the proportion of white-collar workers (27). Due to the high correlations among these indicators $(30,31)$, a principal component score was calculated and named the SES condition. We used a regression method on the SES condition variables, which were standardized with a mean score of 0 and a standard deviation of 1 , to calculate the principal component score of the SES condition. The proportion of the first component variance obtained by principal component analysis was $84.95 \%$ in the Sumida Ward dataset with regression coefficients of $0.38,0.33$, and 0.37 for average household income, proportion of people with higher education, and proportion of white-collar workers, respectively. As for the Fukui Prefecture dataset, the first component variance was $75.57 \%$ and the regression coefficients were $0.36,0.42$, and 0.37 , respectively. 
We assessed population density (population per $\mathrm{km}^{2}$ of inhabitable land area) to adjust for the effect of ruralurban differences, since the area-level number of older adults per 100 residents in Japan tends to progress faster in rural areas than in urban areas (15). All area-level variables were standardized before the analyses were conducted.

\subsubsection{Measurement of individual-level variables}

\subsubsection{Outcome}

SWB was assessed using a Japanese version of the Life Satisfaction Index-A (LSIA) (32) that measures the long-term cognitive evaluation of a person's life as well as transient affective feelings (33). The LSIA has been widely used (33-35) in gerontology studies with non-clinical populations. Liang (34) conducted a confirmatory factor analysis on the 10-item version of the LSIA and concluded that the scale consists of three sub-dimensions: "mood tone," "zest," and "congruence." This three-factor structure was also confirmed in the Japanese version (35). We used the 10-item version of LSIA in Study 2. On the other hand, only the threeitem version of LSIA was available for use in Study 1 as only these items were assessed with the survey. The three items used in Study 1 were selected from the three sub-dimensions of the 10-item version of the LSIA. The items were as follows: "these are the best years of my life" (mood tone), "I expect some interesting and pleasant things to happen to me in the future" (zest), and "as I look back on my life, I am fairly well satisfied" (congruence). We analyzed the correlation between scores of the 10-item and three-item LSIA scales using Study 2 data that yielded a correlation coefficient of 0.84 . Each item in the LSIA had three options scored from 1 (disagree) to 3 (agree), with higher scores reflecting higher life satisfaction. Cronbach's alpha coefficient was 0.68 in Study 1, and 0.74 in Study 2, indicating acceptable internal consistency.

\subsubsection{Individual-level covariates}

We selected individual covariates according to previous studies that focused on the effect of neighborhood characteristics on the psychological health of the elderly $(36,37)$ and factors on $\operatorname{SWB}(4,38)$. As core covariates (39), we assessed age, sex, and years of education (dichotomized as $\geq 9$ years or $<9$ years). In addition, we assessed cohabitation (living alone or not), physical mobility (limited or not), and economic hardship (experienced or not). Physical mobility was assessed by measuring the respondents' abilities to travel independently outside their homes. The survey item originally had six responses ranging from independently using public transportation to being bedbound; however, we excluded respondents who were bedbound from this study. This resulted in respondents who could at least walk around their home independently. Responses were organized into two categories: having the ability to travel by public transportation independently or needing assistance/being unable to travel by public transportation. One item assessed economic hardship by measuring household financial strain that ranged from strongly agree to strongly disagree. The responses of strongly agree, somewhat agree, and neutral were categorized as indicating no economic hardship.

\subsection{Analyses}

We analyzed Studies 1 and 2 in the same manner. The effect of area-level number of older adults per 100 residents on LSIA scores was analyzed using linear mixed-effect modeling. All analyses were computed using restricted maximum likelihood estimation in SPSS version 22.0J for Windows (IBM Japan Ltd., Tokyo, Japan).

First, we examined the unconditional association between the area-level number of older adults per 100 residents and LSIA scores without controlling for the area- and individual-level covariates, except for LSIA scores at baseline (T1) in the longitudinal analysis in Study 2 (Model 1). Second, the area-level SES condition and population density were added to the first model to examine the conditional association between the area-level number of older adults per 100 residents and LSIA scores (Model 2). In the next two models, we sequentially added the individual-level core variables (Model 3) and other individual covariates in addition to the core covariates (Model 4) as the fixed effect variables. In all models, intercepts of fixed (individual) and random (area) effects were included. In this study, $p$ values less than 0.05 (two-tailed) were interpreted as being statistically significant for all analyses.

\subsection{Ethics Statement}

This study was approved by the institutional review boards at the Tokyo Metropolitan Institute of Gerontology, University of Tokyo, and the National Center for Geriatrics and Gerontology. For the interview survey in Sumida Ward, verbal consent, as authorized by the ethics committee, was obtained from the participants prior to conducting the interview. For the self-administered surveys in Fukui Prefecture, we regarded responses as a sign of consent to participate in the survey.

\section{Results}

\subsection{Study 1}

The characteristics of the analyzed respondents ( $n$ $=572)$ and the area-level characteristics $(n=25)$ 
Table 1. Characteristics of participants and districts: Sumida Ward, Tokyo (Study 1)

\begin{tabular}{|c|c|c|}
\hline $\begin{array}{l}\text { Individual-level variables } \\
\text { Variables }\end{array}$ & Category & $\begin{array}{l}(n=572) \\
\text { Mean (SD) or } \%\end{array}$ \\
\hline Age & (in years) & $79.54(3.81)$ \\
\hline \multirow[t]{2}{*}{ Sex } & Male & 37.00 \\
\hline & Female & 63.00 \\
\hline \multirow[t]{3}{*}{ Education in years } & $<9$ years & 61.43 \\
\hline & $\geq 9$ years & 38.05 \\
\hline & Unknown & 0.52 \\
\hline \multirow[t]{2}{*}{ Living arrangement } & Living alone & 23.91 \\
\hline & Living with others & 76.09 \\
\hline \multirow[t]{3}{*}{ Economic hardship } & With hardship & 36.30 \\
\hline & Without hardship & 59.16 \\
\hline & Unknown & 4.54 \\
\hline \multirow[t]{2}{*}{ Physical mobility } & Limited & 26.35 \\
\hline & Not limited & 73.65 \\
\hline Life Satisfaction Index-A & Range: 3-9 & $7.15(1.79)$ \\
\hline \multirow{2}{*}{$\begin{array}{l}\text { District-level variables } \\
\text { Variables }\end{array}$} & & $(n=25)$ \\
\hline & Components of socioeconomic conditions & Median (range) \\
\hline $\mathrm{N}$ adults $65+$ per 100 residents & - & $16.33(13.42-22.31)$ \\
\hline \multirow[t]{3}{*}{ Socioeconomic conditions } & Average household income (JPY 1,000,000) & $6.00(4.20-8.20)$ \\
\hline & Proportion of white-collar workers (\%) & $15.54(10.17-25.14)$ \\
\hline & Proportion of people with higher education (\%) & $31.98(16.52-42.30)$ \\
\hline Population density & - & $18342.11(2998.10-24310.92)$ \\
\hline
\end{tabular}

Note: District-level variables were obtained from 2000 Census (25) except for average household income that was obtained from a survey conducted for residents in Sumida Ward, $2002(29)$.

Table 2. Relationship between area-level number of adults aged 65 years and older per 100 residents and the Life Satisfaction Index-A scores in Sumida Ward (Study 1) $(n=572)$

\begin{tabular}{|c|c|c|c|c|c|c|c|c|}
\hline \multirow{2}{*}{ Items } & \multicolumn{2}{|c|}{ Model 1} & \multicolumn{2}{|c|}{ Model 2} & \multicolumn{2}{|c|}{ Model 3} & \multicolumn{2}{|c|}{ Model 4} \\
\hline & $\mathrm{B}(\mathrm{SE})$ & $p$ & $\mathrm{~B}(\mathrm{SE})$ & $p$ & $\mathrm{~B}(\mathrm{SE})$ & $p$ & $\mathrm{~B}(\mathrm{SE})$ & $p$ \\
\hline \multicolumn{9}{|l|}{ District level } \\
\hline $\mathrm{N}$ adults $65+$ per 100 & $0.11(0.10)$ & 0.273 & $0.21(0.09)$ & 0.019 & $0.21(0.09)$ & 0.021 & $0.24(0.10)$ & 0.042 \\
\hline Socioeconomic conditions & & & $0.23(0.09)$ & 0.014 & $0.21(0.09)$ & 0.021 & $0.20(0.10)$ & 0.071 \\
\hline Population density & & & $-0.05(0.10)$ & 0.616 & $-0.04(0.10)$ & 0.694 & $-0.03(0.11)$ & 0.788 \\
\hline \multicolumn{9}{|l|}{ Individual level } \\
\hline Age (In years) & & & & & $-0.01(0.02)$ & 0.523 & & \\
\hline Sex (Female) & & & & & $0.20(0.16)$ & 0.191 & $0.48(0.16)$ & 0.003 \\
\hline Education in years $(\geq 9$ years) & & & & & $0.27(0.16)$ & 0.087 & $0.20(0.15)$ & 0.182 \\
\hline Living arrangement (Living with others) & & & & & & & $0.49(0.18)$ & 0.006 \\
\hline Economic hardship (Without hardship) & & & & & & & $0.76(0.15)$ & $<0.001$ \\
\hline Physical mobility (Not limited) & & & & & & & $0.67(0.18)$ & $<0.001$ \\
\hline
\end{tabular}

Notes: We conducted all analyses by a linear mixed-model. Intercepts of fixed (individual) and random (district) effects were included in the models. Those who were categorized as unknown in education in years or economic hardship were also included in the analysis. Reference categories were as follows: male (sex), <9 years (education), living alone (living arrangement), with hardship (economic hardship), and limited (physical mobility).

are shown in Table 1. Respondents' mean age was 79.54 years and men comprised $37 \%$ of the sample. Approximately $40 \%$ of the respondents had 9 or more years of education. The majority of participants lived with others, were able to use public transportation independently, and had no economic hardship.

As for the area-level characteristics, the number of people aged 65 years or older per 100 residents ranged between $13.42 \%$ and $22.31 \%$ with a median score of $16.33 \%$. The average household income of each district ranged between JPY 4.20 and 8.20 million (approximately 38,889-75,926 USD, converted using the rate of USD $1=$ JPY 125 , as the average in July 2001, when the survey was conducted). The proportion of people with more than a high school education ranged from $16.52 \%$ to $42.30 \%$ with a median score of $31.98 \%$. Population density per $1 \mathrm{~km}^{2}$ ranged from 2,998.10 to 24,310.92 with a median score of 18,342.11.

The associations between area-level number of older adults per 100 residents and LSIA scores are shown in Table 2. The area-level number of older adults per 100 residents was not significant in the unconditional model 
Table 3. Baseline characteristics of analyzed residents and former municipalities: Fukui Prefecture (Study 2)

\begin{tabular}{|c|c|c|c|}
\hline $\begin{array}{l}\text { Individual-level variables } \\
\text { Variables }\end{array}$ & Category & $\begin{array}{l}\text { Cross-sectional }(n=1,257) \\
\text { Mean }(\mathrm{SD}) \text { or } \%\end{array}$ & $\begin{array}{l}\text { Longitudinal }(n=859) \\
\text { Mean }(\mathrm{SD}) \text { or } \%\end{array}$ \\
\hline Age & (In years) & $80.24(4.43)$ & $79.61(3.92)$ \\
\hline \multirow[t]{3}{*}{ Sex } & Male & 42.72 & 43.89 \\
\hline & Female & 57.20 & 56.00 \\
\hline & Unknown & 0.08 & 0.12 \\
\hline \multirow[t]{3}{*}{ Education in years } & $<9$ years & 53.62 & 51.11 \\
\hline & $\geq 9$ years & 43.20 & 46.45 \\
\hline & Unknown & 3.18 & 2.44 \\
\hline \multirow[t]{3}{*}{ Living arrangement } & Living alone & 9.23 & 8.96 \\
\hline & Living with others & 89.18 & 90.10 \\
\hline & Unknown & 1.59 & 0.93 \\
\hline \multirow[t]{3}{*}{ Economic hardship } & With hardship & 16.55 & 15.72 \\
\hline & Without hardship & 81.46 & 82.89 \\
\hline & Unknown & 1.99 & 1.40 \\
\hline \multirow[t]{2}{*}{ Physical mobility } & Limited & 60.14 & 54.60 \\
\hline & Not limited & 39.86 & 45.40 \\
\hline Life Satisfaction Index-A & Range: $10-30$ & $21.94(3.83)$ & $22.23(3.83)$ \\
\hline \multirow{2}{*}{$\begin{array}{l}\text { District-level variables } \\
\text { Variables }\end{array}$} & \multicolumn{3}{|c|}{$(n=35)$} \\
\hline & Components of socioeconomic conditions & \multicolumn{2}{|c|}{ Median (range) } \\
\hline $\mathrm{N}$ adults $65+$ per 100 residents & - & \multicolumn{2}{|c|}{$27.32(21.02-40.64)$} \\
\hline \multirow[t]{3}{*}{ Socioeconomic conditions } & Average taxable income per taxpayer (JPY $1,000,000$ ) & \multicolumn{2}{|c|}{$3.25(2.73-3.76)$} \\
\hline & Proportion of white-collar workers (\%) & \multicolumn{2}{|c|}{$15.13(9.82-20.86)$} \\
\hline & Proportion of people with higher education (\%) & \multicolumn{2}{|c|}{$23.21(8.97-30.79)$} \\
\hline Population density & - & \multicolumn{2}{|c|}{$463.12(22.50-1422.20)$} \\
\hline
\end{tabular}

Note: Former municipality-level variables were obtained using 2010 Census (27). Average taxable income per taxpayer (JPY 1,000,000) was obtained from Regional Statistics provided by the Statistics Bureau of Japan (1998) (25).

(Model 1). However, in Model 2 when other area-level variables were controlled, the number of older adults per 100 residents had a significantly positive effect on LSIA scores $(p=0.019)$. Further in the next two models that adjust the effect of core and other individual covariates, the number of older adults per 100 residents had a significantly positive effect on LSIA scores $(p=$ 0.021 in Model 3; $p=0.042$ in Model 4, respectively).

\subsection{Study 2}

For the cross-sectional analysis $(n=1,257)$, respondents' mean age was 80.24 years and men comprised $42.72 \%$ of the sample. While the sample characteristics were similar to those of Study 1 in that the majority of respondents lived with others and had no economic hardship, it differed, in that more than $60 \%$ of respondents were unable to use public transportation independently. The baseline characteristics of respondents in the longitudinal analysis $(n=859)$ were similar in age, gender, education in years, and other variables to those in the crosssectional analysis, except for physical mobility, which was more independent for those in the longitudinal analysis.

Regarding area-level characteristics, the proportion of older people ranged from $21.02 \%$ to $40.64 \%$ with a median score of $27.32 \%$. As for SES condition, the proportion of people with higher education ranged from $8.97 \%$ to $30.79 \%$ with a median score of $23.21 \%$.
Population density ranged from 22.50 to 1422.20 with a median score of 463.12 (Table 3).

Table 4 and Table 5 show the associations between the area-level proportion of older people and LSIA scores in the cross-sectional and longitudinal analyses. In the cross-sectional analysis (Table 4), a marginally positive correlation was observed in Model 2 with an unstandardized coefficient of $0.50(p<0.074)$. The coefficient decreased to 0.47 in Model 3, controlling for the individual-level core variables of age, sex, and education $(p<0.100)$, and to 0.37 in Model 4 , after adding physical mobility, economic hardship, and cohabitation to Model 3 ( $p<0.130)$. On the other hand, in the longitudinal analysis (Table 5), the area-level number of older adults per 100 residents was marginally and positively associated with LSIA scores at follow-up ( $p=0.055)$, controlling for LSIA at baseline (Model 1). The area-level number of older adults per 100 residents still had a significant and positive association with LSIA scores in Models 2, 3, and 4 ( $p=0.027, p=0.042$, and $p=0.049$, respectively).

\section{Discussion}

This study showed that area-level population aging was positively associated with higher SWB of senior residents in both a metropolitan cross-sectional dataset and an urban-rural longitudinal dataset. These correlations were significant when the area-level SES 
Table 4. Relationships between area-level number of adults aged 65 years and older per 100 residents and the Life Satisfaction Index-A scores in Fukui Prefecture (Study 2: cross-sectional analysis) $(n=1,257)$

\begin{tabular}{|c|c|c|c|c|c|c|c|c|}
\hline \multirow{2}{*}{ Items } & \multicolumn{2}{|c|}{ Model 1} & \multicolumn{2}{|c|}{ Model 2} & \multicolumn{2}{|c|}{ Model 3} & \multicolumn{2}{|c|}{ Model 4} \\
\hline & $\mathrm{B}(\mathrm{SE})$ & $p$ & $\mathrm{~B}(\mathrm{SE})$ & $p$ & B (SE) & $p$ & $\mathrm{~B}(\mathrm{SE})$ & $p$ \\
\hline \multicolumn{9}{|l|}{ Former municipality level } \\
\hline $\mathrm{N}$ adults $65+$ per 100 & $0.21(0.14)$ & 0.182 & $0.50(0.21)$ & 0.074 & $0.47(0.24)$ & 0.100 & $0.37(0.19)$ & 0.130 \\
\hline Socioeconomic conditions & & & $0.11(0.19)$ & 0.596 & $0.10(0.22)$ & 0.654 & $-0.06(0.17)$ & 0.739 \\
\hline Population density & & & $0.30(0.20)$ & 0.172 & $0.29(0.22)$ & 0.219 & $0.36(0.18)$ & 0.087 \\
\hline \multicolumn{9}{|l|}{ Individual level } \\
\hline Age (In years) & & & & & $-0.06(0.02)$ & 0.021 & $-0.05(0.02)$ & 0.026 \\
\hline Sex (Female) & & & & & $0.73(0.22)$ & 0.001 & $0.88(0.21)$ & $<0.001$ \\
\hline Education in years ( $\geq 9$ years) & & & & & $0.60(0.22)$ & 0.007 & $0.25(0.21)$ & 0.248 \\
\hline Living arrangement (Living with others) & & & & & & & $1.38(0.37)$ & $<0.001$ \\
\hline Economic hardship (Without hardship) & & & & & & & $2.87(0.28)$ & $<0.001$ \\
\hline Physical mobility (Not limited) & & & & & & & $1.04(0.22)$ & $<0.001$ \\
\hline
\end{tabular}

Notes: We conducted all analyses by a linear mixed-model. Intercepts of fixed (individual) and random (districts) effects were included in the models. Those who were categorized as unknown in sex, education in years, living arrangement, or economic hardship were also included in the analysis. Reference categories were as follows: male (sex), < 9 years (education), living alone (living arrangement), with hardship (economic hardship), and limited (physical mobility)

Table 5. Relationship between area-level number of adults aged 65 years and older per 100 residents and the Life Satisfaction Index-A scores in Fukui Prefecture (Study 2: longitudinal analysis) $(n=859)$

\begin{tabular}{|c|c|c|c|c|c|c|c|c|}
\hline \multirow{2}{*}{ Items } & \multicolumn{2}{|c|}{ Model 1} & \multicolumn{2}{|c|}{ Model 2} & \multicolumn{2}{|c|}{ Model 3} & \multicolumn{2}{|c|}{ Model 4} \\
\hline & B (SE) & $p$ & $\mathrm{~B}(\mathrm{SE})$ & $p$ & $\mathrm{~B}(\mathrm{SE})$ & $p$ & $\mathrm{~B}(\mathrm{SE})$ & $p$ \\
\hline \multicolumn{9}{|l|}{ Former municipality level } \\
\hline $\mathrm{N}$ adults $65+$ per 100 & $0.22(0.11)$ & 0.055 & $0.39(0.18)$ & 0.027 & $0.37(0.18)$ & 0.040 & $0.35(0.18)$ & 0.049 \\
\hline Socioeconomic conditions & & & $0.07(0.15)$ & 0.667 & $0.02(0.15)$ & 0.918 & $-0.02(0.15)$ & 0.911 \\
\hline Population density & & & $0.15(0.17)$ & 0.384 & $0.14(0.17)$ & 0.394 & $0.16(0.17)$ & 0.343 \\
\hline \multicolumn{9}{|l|}{ Individual level } \\
\hline Life Satisfaction Index-A scores at baseline & $0.62(0.03)$ & $<0.001$ & $0.62(0.03)$ & $<0.001$ & $0.60(0.03)$ & $<0.001$ & $0.58(0.03)$ & $<0.001$ \\
\hline Age (In years) & & & & & $-0.06(0.03)$ & 0.021 & $-0.05(0.03)$ & 0.056 \\
\hline Sex (Female) & & & & & $0.39(0.21)$ & 0.061 & $0.50(0.21)$ & 0.019 \\
\hline Education in years ( $\geq 9$ years) & & & & & $0.56(0.21)$ & 0.007 & $0.42(0.21)$ & 0.045 \\
\hline Living arrangement (Living with others) & & & & & & & $0.15(0.36)$ & 0.691 \\
\hline Economic hardship (Without hardship) & & & & & & & $0.41(0.29)$ & 0.159 \\
\hline Physical mobility (Not limited) & & & & & & & $0.67(0.21)$ & 0.002 \\
\hline
\end{tabular}

Notes: We conducted all analyses by a linear mixed-model. Intercepts of fixed (individual) and random (districts) effects were included in the models. The outcome variable was Life Satisfaction Index-A scores in the follow-up survey. Those who were categorized as unknown in sex, education in years, living arrangement, or economic hardship were also included in the analysis. Reference categories were as follows: male (sex), $<9$ years (education), living alone (living arrangement), with hardship (economic hardship), and limited (physical mobility).

conditions and population density were invariable. Moreover, the effect of area-level population aging was still significant after controlling for individual characteristics.

These findings support those of previous studies on the effect of area-level population aging on selfrated overall health (12), self-rated oral health (14), and depression (36) that targeted older adults living in general communities. One possibility for the findings in this study is that areas with more population aging tend to be more socially cohesive with lower residential mobility $(40,41)$. Another possibility is that those areas could provide senior residents with more social interactions with peers of a similar age who share similar values and experiences (13). Vogelsang and Raymo (17) also showed that older adults living in areas with more population aging were more likely to engage in paid work. On the other hand, it may not be relevant for the findings of this study that local areas with more progressed population aging could have more extensive elderly services (12), because these areas in Japan are generally more rural than urban (15), where services and infrastructure for senior residents are less likely to be available.

The "health and place" literature indicates that frequent geographical mobility by the respondents can confound research results. One of the strengths of this study is that our datasets did not suffer from this methodological issue (17). The residential mobility rate of older adults in Japan is much lower than that of both the younger population in Japan (42) and older adults from the US or UK $(43,44)$. In this study, the majority 
of our respondents lived for a very long period in their communities (detailed results are available upon request). Furthermore, we found that analyses from the two distinct surveys showed a similar positive effect of local-area population aging on the SWB of senior residents. This suggests that our findings indicate crossvalidity in the effect of area-level population aging on the SWB of older adults. This study also showed a significant effect of area-level population aging using a longitudinal study design, whereas the majority of previous studies only used a cross-sectional design to examine the relationship $(12,14,36)$. Our study demonstrated that local-area population aging was positively related to SWB changes over time.

At the same time, we should discuss three limitations to our study. First, the dataset from a metropolitan area and those from urban-rural areas are neither identical in the survey method, period, range of the area-level population aging, nor in the level of areas. Therefore, we should compare the findings with much caution. Second, the generalizability of the datasets remains limited even though we showed similar findings by analyzing the data obtained from two distinct survey projects, because they were from a ward and a prefecture in Japan. Lastly, we should have discussed areas analyzed from a proximal level. In this study, we regarded a district as the arealevel in Study 1 because a district was similar to the area where the elderly residents spent their daily lives (24), and it also corresponded to the administrative units in the study area where civic organizations were established or local events were organized. On the other hand, Study 2 used former municipal units. Although Study 2 showed a significant and positive effect of area-level population aging in its longitudinal analysis, a weaker association was observed in the cross-sectional analysis. Our tentative interpretation for this is that district-level population aging could be more appropriate than the former municipal level when examining the effect on the SWB of senior residents. Municipal units could be broader than the area of senior residents' daily living space and include several communities with different levels of population aging. In addition, different policies or systems by their governments may have confounded the findings. Therefore, future studies should use a more complex analytical design, such as a three-level mixed model that includes individual-, neighborhood-, and municipality-level variables to examine the proximal level of local-area population aging.

Despite its limitations, this study contributes meaningful findings to the present literature. The results showed the importance of population aging in local areas on SWB among older adults in inner city, rural, and urban areas in a non-Western culture. Future studies should explore the pathways (i.e., area-level social cohesion or psychosocial resources of older individuals) that intervene in the relationship between area-level characteristics and the well-being and health of older adults. In addition, we recommend establishing a proximal level of population aging in hopes of improving older adults' SWB. Furthermore, proactively determining certain people that might be prone to environmental characteristics would be the next issue. The findings of our study create important implications for the recent efforts on residential migration by the Japanese government. To decrease urban-rural differences and revitalize underpopulated regions, the Japanese government has recently organized a national assembly to discuss how to promote migration of citizens from metropolitan regions to more rural areas (45). However, findings from our study showed that in areas with lower population aging, where younger generations are dominant, older adults are more likely to have lower SWB. This implies that a rapid inflow of the younger generation could result in negative consequences for the SWB of senior residents. In urban renovation and the development of communities, policymakers and professionals working with older adults should consider the subjective well-being and health of their senior residents. Additionally, communities where older adults are a small minority should promote services for them to remain active and maintain their purpose in life to improve their SWB.

\section{Acknowledgements}

This study was supported by Grants-in-Aid for Scientific Research (Nos. 22689022, 23390127, 25713027, and 13410071) from the Japan Society for the Promotion of Science.

We would like to thank Prof. Tatsuto Asakawa for designing and implementing the Sumida Ward survey in this study. We also sincerely thank Prof. Takuhiro Yamaguchi and Dr. Tomoko Wakui for their insightful comments and suggestions on the earlier version of this manuscript.

\section{References}

1. Diener E, Suh MS, Lucas RE, Smith HL. Subjective well-being: Three decades of progress. Psychol Bull. 1999; 125:276-302.

2. George LK. Perceived quality of life. In: Handbook of Aging and the Social Sciences. ( $6^{\text {th }}$ ed.) (Binstock RH, George LK, eds.). Academic Press, Burlington, USA, 2006; pp. 321-336.

3. George LK. Subjective well-being: Conceptual and methodological issues. Annu Rev Gerontol Geriatr. 1981; 2:345-382.

4. Larson R. Thirty years of research on the subjective wellbeing of older Americans. J Gerontol. 1978; 33:109-125.

5. Brown V. The effect of poverty environments on elders' subjective well-being: A conceptual model. Gerontologist. 1995; 35:541-548.

6. Glass TA, Balfour JL. Neighborhoods, aging, and functional limitations. In: Neighborhoods and Health (Kawachi I, Berkman LF, eds.). Oxford University Press, 
New York, USA, 2003; pp.303-334.

7. McGhee JL. The Influence of qualitative assessments of the social and physical environment on the morale of the rural elderly. Am J Community Psychol. 1984; 12:709722.

8. Sheidt RJ, Windley PG. The mental health of small-town rural elderly residents: An expanded ecological model. J Gerontol. 1983; 38:472-479.

9. Lawton MP, Yaffe S. Victimization and fear of crime in elderly public housing tenants. J Gerontol. 1980; 35:768779 .

10. Lawton MP, Moss M, Moles E. The suprapersonal neighborhood context of older people: Age heterogeneity and well-being. Environ Behav. 1984; 16:89-109.

11. Lawton MP, Nahemow L. Social areas and the wellbeing of tenants in housing for the elderly. Multivariate Behav Res. 1979; 14:463-484.

12. Subramanian SV, Kubzansky L, Berkman L, Fay M, Kawach I. Neighborhood effects on the self-rated health of elders: Uncovering the relative importance of structural and service-related neighborhood environments. J Gerontol B Psychol Sci Soc Sci. 2006; 61B:S153-S160.

13. Lawton MP. Environment and aging. (2nd ed.) Albany: Center for the Study of Aging, USA, 1986.

14. Widener MJ, Metcalf SS, Northridge ME, Chakraborty B, Marshall SM, Lamster IB. Exploring the role of peer density in the self-reported oral health outcomes of older adults: A kernel density based approach. Health Place. 2012; 18:782-788.

15. Cabinet Office of Japan Annual report on the aging society: 2015. Nikkei Printing Inc., Tokyo, Japan 2015. (In Japanese).

16. Muramatsu N, Akiyama H. Japan: Super-aging society preparing for the future. Gerontologist. 2011; 51:425432.

17. Vogelsang EM, Raymo JM. Local-area age structure and population composition: Implications for elderly health in Japan. J Aging Health. 2014; 26:155-177.

18. Kobayashi T, Suzuki E, Noguchi M, Kawachi I, Takao S. Community-level social capital and psychological distress among the elderly in Japan: A population-based study. PLoS One. 2015; 10:e142629.

19. Murayama H, Nofuji Y, Matsuo E, Nishi M, Taniguchi Y, Fujiwara Y, Shinkai S. Are neighborhood bonding and bridging social capital protective against depressive mood in old age? A multilevel analysis in Japan. Soc Sci Med. 2015; 124:171-179.

20. Saito M, Kondo K, Kondo N, Abe A, Ojima T, Suzuki $\mathrm{K}$, JAGES group. Relative deprivation, poverty, and subjective health: JAGES cross-sectional study. PLoS One. 2014; 9:e111169.

21. Murayama H, Fujiwara Y, Kawachi I. Social capital and health: A review of prospective multilevel studies. J Epidemiol. 2012; 22:179-187.

22. Wight RG, Cummings JR, Karlamangla AS, Aneshensel CS. Urban neighborhood context and change in depressive symptoms in late life. J Gerontol B Psychol Sci Soc Sci. 2009; 64:247-251.

23. Arisue K. Multilayered structure of contemporary metropolitan cities: Tradition and transition in urban societies. Minerva Shobo, Tokyo, Japan, 1999. (In Japanese).

24. Ohata M, Kayaba K, Maruyama Y, Otsuka M. Living areas perceived by healthy elderly people living in the suburbs of a metropolitan area. Nihon Koshu Eisei Zasshi. 2006; 53:899-906. (In Japanese)

25. Statistics Bureau of Japan. Regional statistics. http:// www.e-stat.go.jp/SG1/chiiki/Welcome.do?lang $=02$ (accessed Nov 25, 2015). (In Japanese)

26. Saito T, Wakui T, Kai I. Effects of spousal illness on self-rated health in older couples: Role of gender and proximity to adult children. Geriatr Gerontol Int. (in press)

27. Statistics Bureau of Japan. Population Census. http:// www.e-stat.go.jp/SG1/estat/GL32020101.do? method $=e$ xtendTclass\&refTarget $=$ toukeihyo\&listFormat $=$ hierarc hy\&statCode $=00200521 \&$ tstatCode $=\&$ tclass $1=\&$ tclas $s 2=\&$ tclass $3=\&$ tclass $4=\&$ tclass $5=($ accessed Nov 25 , 2015). (In Japanese)

28. Galea S, Ahern J, Nandi A, Tracy M, Beard J, Vlahov D. Urban neighborhood poverty and the incidence of depression in a population-based cohort study. Ann Epidemiol. 2007; 17:171-179.

29. Saito T. A multilevel analysis on relationships between neighborhood social characteristics and depression and subjective well-being of the old-old living in an urban city area. Thesis, the University of Tokyo, Japan, 2010. (In Japanese)

30. Silver E, Mulvey EP, Swanson JW. Neighborhood structural characteristics and mental disorder: Faris and Dunham revisited. Soc Sci Med. 2002; 55:1457-1470.

31. Walters K, Breeze E, Wilkinson P, Price GM, Bulpitt CJ, Fletcher A. Local area deprivation and urban-rural differences in anxiety and depression among people older than 75 years in Britain. Am J Public Health. 2004; 94:1768-1774.

32. Neugarten BL, Havighurst RJ, Tobin SS. The measurement of life satisfaction. J Gerontol. 1961; 16:134-143.

33. Lawrence RH, Liang J. Structural integration of the Affect Balance Scale and the Life Satisfaction Index A: Race, sex, and age differences. Psychol Aging. 1988; 3:375-384.

34. Liang J. Dimensions of the Life Satisfaction Index A: A structural formulation. J Gerontol. 1984; 39:613-622.

35. Saito T, Sugisawa H, Sugihara Y, Okabayashi H, Shibata $\mathrm{H}$. The impact of relocation on well-being of the elderly. Nihon Koshu Eisei Zasshi. 2000; 47:856-865. (In Japanese)

36. Kubzansky LD, Subramanian SV, Kawachi I, Fay ME, Soobader MJ, Berkman LF. Neighborhood contextual influences on depressive symptoms in the elderly. Am J Epidemiol. 2005; 162:253-260.

37. Muramatsu N. County-level income inequality and depression among older Americans. Health Serv Res. 2003; 38:1863-1883.

38. George LK. Still happy after all these years: Research frontiers on subjective well-being in later life. J Gerontol: Soc Sci. 2010; 65B:331-339.

39. Glymour MM, Mujahid M, Wu Q, White K, Tchetgen EJ. Neighborhood disadvantage and self-assessed health, disability, and depressive symptoms: Longitudinal results from the health and retirement study. Ann Epidemiol. 2010; 20:856-861.

40. Cagney KA, Browning CR, Wen M. Racial disparities in self-rated health at older ages: What difference does the neighborhood make? J Gerontol B: Psychol Sci Soc Sci. 2005; 60:S181-S190.

41. Ross CE, Reynolds JR, Geis KJ. The contingent meaning 
of neighborhood stability for residents' psychological well-being. Am Sociol Rev. 2000; 65:581-597.

42. Statistics Bureau of Japan. Residential mobility of older people. http://www.stat.go.jp/data/topics/topi902.htm (accessed Nov 26, 2015). (In Japanese)

43. He W, Schachter JP. Internal migration of the older population: 1995 to 2000. United States Census 2000, Washington DC, USA, 2003; pp. 1-11.

44. Glaser K, Grundy E. Migration and household change in the population aged 65 and over, 1971-1991. Int. J. Popul. Geogr. 1998; 4:323-339.

45. Prime Minister of Japan and His Cabinet. Headquarters for promoting decentralization reform. http://japan. kantei.go.jp/index.html. (accessed Nov 25, 2015). (In Japanese)

(Received December 17, 2015; Revised February 29, 2016; Accepted March 2, 2016) 